\title{
Instructors' reasons for choosing problem features in a calculus-based introductory physics course
}

\author{
Edit Yerushalmi and Elisheva Cohen \\ Department of Science Teaching, Weizmann Institute of Science, Rehovot 76100, Israel \\ Kenneth Heller \\ School of Physics and Astronomy, University of Minnesota, Minneapolis, Minnesota 55455, USA \\ Patricia Heller \\ Department of Curriculum and Instruction, University of Minnesota, Minneapolis, Minnesota 55455, USA \\ Charles Henderson \\ Department of Physics and Mallinson Institute for Science Education, Western Michigan University, \\ Kalamazoo, Michigan 49008-5252, USA \\ (Received 14 March 2010; published 25 August 2010)
}

\begin{abstract}
This study investigates how the beliefs and values of physics faculty influence their choice of physics problems for their students in an introductory physics course. The study identifies the goals these instructors have for their students, the problem features they believe facilitate those goals, and how those features correspond to problems they choose to use in their classes. This analysis comes from an artifact-based interview of 30 physics faculty teaching introductory calculus-based physics at a wide variety of institutions. The study concludes that instructors' goals and the problem features they believe support those goals align with researchbased curricular materials intended to develop competent problem solvers. However, many of these instructors do not use the beneficial problem features because they believe these features conflict with a more powerful set of values concerned with clarity of presentation and minimizing student stress, especially on exams.
\end{abstract}

DOI: 10.1103/PhysRevSTPER.6.020108

PACS number(s): 01.40.gb

\section{INTRODUCTION}

Three central goals are presented in the educational literature for using problems in the introductory physics course as a means of: (1) helping students construct physics knowledge $[1,2]$, (2) helping students develop generalized problem-solving skills [3]; and (3) introducing students to the nature of scientific culture [4]. The form and content of those problems directly impact what students learn in the course, especially when problem solving is the primary assessment tool. Ideally, specific problem features would emphasize the learning goals of the course. For example, multistep problems that avoid explicit physics cues [5-7] can focus students on the underlying physics concepts useful in that problem situation. Such problems promote the integration of conceptual knowledge and the skills of planning and evaluation. Because of their complexity, these problems often require guidance and feedback (coaching) to allow the novice student to progress [8-10]. Another example is qualitative problems that are used to help students construct their conceptual understanding by requiring predictions and explanations. These problems prevent students from simply manipulating formulas $[11,12]$ to arrive at a solution.

This paper presents a study designed to determine what problem features physics faculty value, whether those features are consistent with their goals for their introductory physics course, whether they use problems with those features in their course, and the extent to which their valued problem features and goals are aligned with those in the educational literature. The study involves an analysis of inter- views with 30 physics instructors who were given 5 alternative problem versions (Figs. 1 and 2) and asked about their preferences regarding the use of these problem formats and the reasons underlying their preferences. The instructors came from a variety of institutions: large state research universities, primarily undergraduate state universities, primarily undergraduate private colleges and community colleges. The information from this analysis can help curriculum developers in designing problems that will be both valued and used by instructors, and help professional development leaders address instructors' concerns regarding problem formats. It may also help instructors reflect upon their goals for using problems and whether their problems support the goals of their teaching.

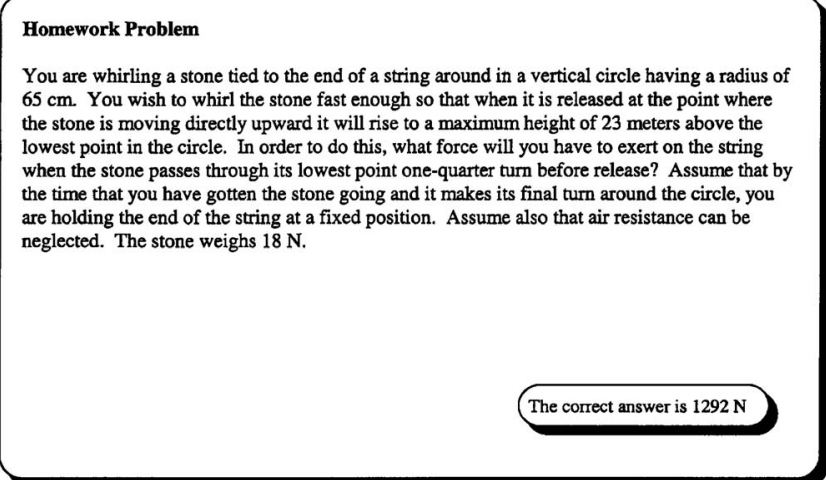

FIG. 1. "Core problem" that instructors were asked to solve prior to the interview. 


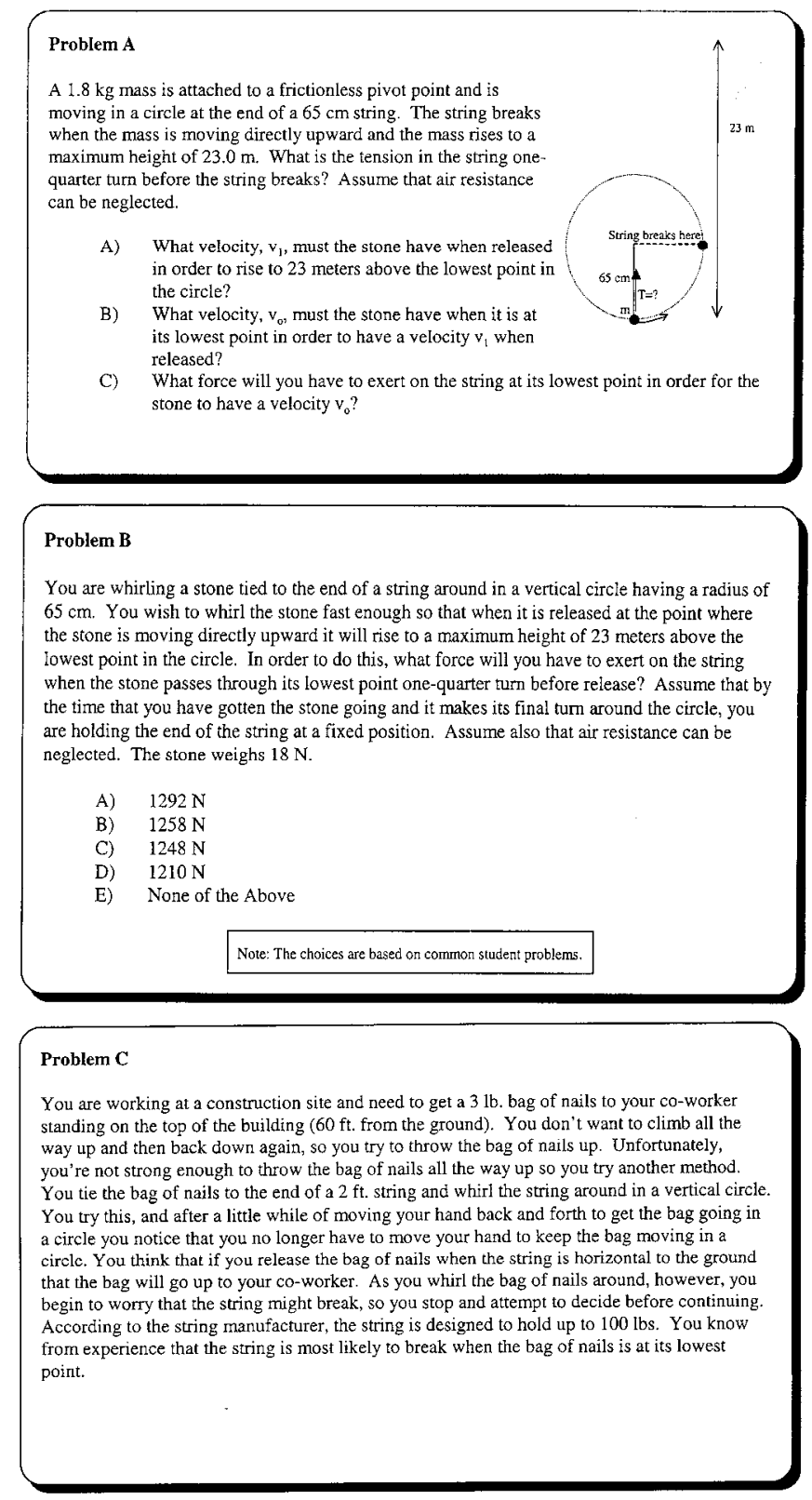

Problem D

You are whirling a stone tied to the end of a string around in a vertical circle of radius $\mathrm{R}$. You wish to whirl the stone fast enough so that when it is released at the point where the stone is moving directly upward it will rise to a maximum height, $\mathrm{H}$, above the lowest point in the circle. In order to do this, what force will you have to exert on the string when the stone passes through its lowest point one-quarter turn before release? Assume that by the time that you have gotten the stone going and it makes its final turn around the circle, you are holding the end of the string at a fixed position. Assume also that air resistance can be neglected.

A) For each point labeled in the diagram, circle the symbol(s) that describe how the speed of the stone is changing.

\begin{tabular}{|c|c|c|c|c|c|}
\hline Point & \multicolumn{5}{|c|}{ Change in Speed } \\
\hline A & & $=$ & & $\max$ & $\min$ \\
\hline B & $t$ & $=$ & & $\max$ & $\min$ \\
\hline $\mathrm{C}$ & & $=$ & & $\max$ & $\min$ \\
\hline $\mathrm{D}$ & 1 & $=$ & & $\max$ & $\min$ \\
\hline E & 1 & $=$ & & $\max$ & $\min$ \\
\hline
\end{tabular}

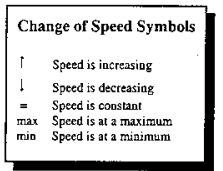

At each point on the diagram, draw and label a vector representing the acceleration of the stone.

C) At each point, draw and label vectors to represent all of the forces acting on the stone.

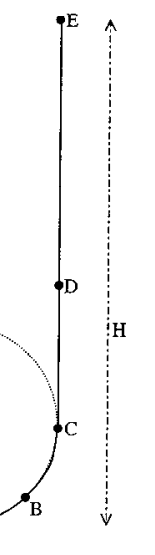

FIG. 2. Four problem variations that instructors were shown during the interview.

To frame the results discussed in this paper, we suggest that readers begin by looking at the alternative problem versions (Figs. 1 and 2), reflect on how these problems are similar or different to the problems they use, and then try to articulate their reasons for favoring particular problem features. Assume that these problems are designed for a calculus-based introductory physics class.

\section{BACKGROUND}

Research-based curricular materials that emphasize problem solving are intended to move students toward more expertlike behavior. It is recognized that one year of physics is not enough time to cause students to become expert problem solvers. The goal is to move them from novice behavior into an intermediate state that is sometimes called competent problem solving [13]. This section provides a brief overview of how experts approach problem solving and what problem types are best suited to help students develop these expertlike approaches.

\section{A. How do experts approach problem solving?}

Experts devote considerable time to first analyzing a problem qualitatively and describing the situation in terms of physics principles [14-18]. Novices, on the other hand, often use surface features to characterize a problem $[19,20]$, such as an inclined plane or free-fall problem. Expert problem solutions have a strategic approach [21] rather than the novice approach of plugging numbers into formulas. Experts plan the process of searching for a solution by identifying useful subproblems and relationships guided by physics prin- 
ciples. Novices, on the other hand, perceive each solution step as an independent entity [22]. Experts also use the problem-solving process as a learning opportunity, reflecting on their solutions to refine their understanding of the related concepts and principles, an aspect missing in novices [23].

\section{B. What problem features are best suited to develop an expertlike approach?}

In order for students to develop expertlike approaches to problem solving, the problems they are asked to solve must require such approaches. In particular, they should require a qualitative analysis, planning, and reflection. Unfortunately, the types of problems most accessible to physics instructors, those in textbooks, frequently lack these characteristics and can often reinforce detrimental novice approaches. Examples of such problems are those without a context, or a context that uses a previously encountered surface structure. In addition, complex problems are often broken down into predetermined parts, thus bypassing the students' need to practice essential strategic skills. Textbooks do give students many useful exercises, but these alone will not move a novice toward expert problem solving, nor do they usually enhance conceptual learning [24,25].

Alternatives to such types of problems exist. These emphasize one or more of the problem-solving skills in which novices are weak. Examples are Context-Rich Problems [5], Experiment Problems [26], Real-world Problems [27], and Thinking Problems [28]. These problems typically are presented in a real-world context, require more than one step to solve, are not accompanied by diagrams, and may contain either more or less information than is needed to solve them. They require students to practice making decisions by analyzing the problem situation, identifying the physics concepts needed to solve the problem, decomposing the problem into subproblems as needed, planning the execution of the solution, and evaluating the results of the solution.

Some curriculum developers also advocate the use of qualitative problems that are constructed to bring out student difficulties understanding fundamental physics concepts. Such questions are used to carefully build from student alternative conceptions to correct conceptions such as in Tutorials [29], to stimulate discussion such as in Peer Instruction [12] or to make students explicitly reflect on their thoughts such as in Troubleshooting Tasks [30-32].

Much is known about efficacy of these alternative types of problems $[5,6,10,33,34]$ and the weaknesses of problems typically found in textbooks [23]. Nevertheless, textbooktype problems continue to be selected by introductory physics instructors for practice and exams in their courses.

\section{DATA COLLECTION AND ANALYSIS}

An artifact-based, structured interview of physics faculty provided the raw data for this study [35]. This section briefly describes the background of the physics instructors who participated in the interview, the data collection procedures, and an overview of the data analysis.

\section{A. Interview participants}

The 30 physics faculty in the interview sample was approximately evenly divided among four groups based on their type of institution: Community College (CC), Primarily Undergraduate Private College (PC), Primarily Undergraduate State University (SU) and Research Oriented State University (RU). They were randomly selected from a pool of 107 tenured or tenure-track faculty in Minnesota who had taught an introductory calculus-based physics course within the last 5 years and could be visited by an interviewer in a day trip from the University of Minnesota, Twin Cities Campus. All but two instructors were male. Their teaching experience as well as their experience teaching the introductory calculus-based class ranged from a few years to a few dozen years.

\section{B. Data collection}

The structured interview protocol used in this study asked instructors to compare a series of concrete instructional artifacts, similar to those they were likely to encounter in their teaching environment, and to make judgments about them. Comparison among artifacts encouraged introspection while using natural language and avoiding leading questions. Three types of instructional artifacts were used: problem statements, instructor solutions, and student solutions. Each interview took about $1.5 \mathrm{~h}$ to complete. A video camera recorded both verbal and visual responses. Written transcripts were made of the interviews and checked as necessary with the original video and audio recordings. In this paper we focus on one part of the interview (typically lasting 20-30 min) in which instructors were given four different variations of a core problem. Prior to the interview, each instructor was given the core problem as "homework" (see Fig. 1) and was asked to solve it. The core problem was taken from a final exam for the introductory calculus-based physics course at the University of Minnesota. It was designed and approved by a group of four physics faculty who taught the course. Its solution requires several important physics concepts (e.g., linear and circular kinematics, dynamics, and energy conservation), and students could potentially work the problem in different ways.

The four variations of the core problem are shown in Fig. 2 . They differ in the reasoning process they require the student to engage in while solving them. For example, Problem $\mathrm{C}$ is phrased as a story, deals with real objects, does not include a diagram or hints, and requires the student to divide the problem into subproblems. Problem A, on the other hand, is divided into subproblems, includes hints and a diagram, and is phrased in an abstract form. To allow for a rich set of ideas to emerge from the interview, none of the problems were designed to be an ideal example of its type.

The interviewees were asked to examine the problem variations. They were first asked: "Please describe how these problems are similar or different to problems you give to your students. Please explain why you use the problems that you use." If necessary a probing question was added: "Do the problems you give students look different in different situations (lecture, homework, exam, beginning or end of 
course...)? How and Why?" Later on they were asked: "Different ways of asking problems require different things from students. Comparing these problems to the homework problem, are there things a student needs to know or be able to do when solving these problems that are not required in solving the homework problem? Do you see any things that the homework problem requires that you have not yet mentioned?"

\section{Data analysis}

For each interviewee we constructed a table representing: (a) the features the instructors identified in each problem; (b) their stated use of problems with these features, (c) their preferences regarding each feature; and (d) their reasons for their preferences. Reasons were categorized and, as described in the next section, often included instructional goals. Each transcript was analyzed by a pair of the authors (EC and either EY or $\mathrm{CH}$ ). Small discrepancies in the classification of statements were resolved between that pair and larger differences were resolved jointly by all the researchers. The classifications were reviewed by all of the authors.

Once the analysis was completed for each of the individual instructors, the data were compiled to determine the valued problem features, the instructors' goals, the extent to which the valued problem features were used, and differences between instructor responses from the four different types of institutions.

\section{RESULTS}

The study results are presented in the four sections below. The first two sections describe the most common problem features identified by the instructors, and the instructors' goals for using problems in their introductory physics course. The third section describes how the instructors' value specific problem features based on whether they believe the feature promotes or hinders their goals. This section also describes the instructors' usage of the valued problem features. Finally, the last section describes why many instructors do not use problem features that they believe promote their goals and use features that they believe hinder their goals.

When the faculty examined the four problem variations (Fig. 2), seven problem features were most frequently mentioned. The numbers in parentheses after each named feature indicate how many instructors mentioned the feature.

(1) Qualitative (27 instructors). The problem does not require a calculation. This feature was usually mentioned in the context of problem D: "There's no calculation involved... just understanding increase, decrease, label them" (I11, PD [Instructor 11, Problem D]); or " ...it requires the students to think more qualitatively.... Without resorting to a formula." (I9, PD)

(2) Multiple Choice (26 instructors). The students choose from among given answers. This feature was usually mentioned in the context of problem B.

(3) Broken into Parts (25 instructors). A complex problem is broken down into several questions that the student answers sequentially. This feature was usually mentioned in the context of problems $\mathrm{A}$ and D.
(4) Real-world Context (22 instructors). The problem statement has a context that simulates situations that students identify as realistic. This feature was usually mentioned in the context of problem $\mathrm{C}$ or the core problem.

(5) Wordy (21 instructors). The problem statement has irrelevant words that might obscure the underlying problem. This feature was usually mentioned in the context of problem C.

(6) Given drawing (18 instructors). The problem statement includes a picture that explains the situation. This feature was usually mentioned in the context of problem A.

(7) Complex or Multistep (10 instructors). The problem solution requires the student to connect several elements of the situation or different physics principles. This feature was usually mentioned in the context of problem $\mathrm{C}$.

\section{A. Instructors' goals}

When faculty examined the different problem variations, they often had a preference for some problem features over others. Many of these preferences were related to learning or teaching goals held by the instructors. The two learning goals most mentioned by instructors as influencing their preferences were developing students' physics understanding and developing students' ability to plan and explore solution paths.

Learning Goal 1: Developing students' physics understanding (27 instructors). Almost all of the instructors related specific problem features to the development of student understanding of physics content. For example: “... and so that's a nice set of questions which requires the students to think about the physics principles behind this problem." (I1, PD)

Learning Goal 2: Developing students' ability to plan and explore solution paths (26 instructors). Almost all of the instructors also related specific problem features to the development of students' problem-solving skill in planning and exploring solution paths. For example: "Again, I find one of the premiere kinds of problem-solving abilities I try to strive for is this notion that a person can read a physical circumstance, and bring together the notions on their own ...I'm hoping that they can put the ideas together themselves." (I2, PA); and "... a bit of thinking process, of course, to formulate the steps." (I3, PC); and "They have to know what the question is and then they also have to be able to define the target variable." (I4, PD)

Instructors also mentioned three types of teaching goals supported by particular problem features. These were motivating students, monitoring students' thinking, and leading students (or not leading them) through a problem.

Teaching Goal 1: Motivating students (21 instructors). Many instructors thought that the problems they asked students to solve should serve a motivational purpose, most commonly invoked by using real-world contexts. For example: "Well, a lot of students don't see the purpose in any of this stuff. It's too academic, right. They're [problem C] trying to show you that what we're asking you to do relates to the real world and may have some consequences, may have some practical benefits, right. And then if the student is 


\begin{tabular}{|l|l|l|c|}
\hline Problem Feature & Legend & Feature & Legend \\
\hline qualitative & & broken into parts & \\
\hline real-world context & & given drawing & \\
\hline wordy & & multiple choice & \\
\hline Complex and/or multi-step & & & \\
\hline
\end{tabular}

FIG. 3. (Color) Legend for problem features in Figs. 4-10.

on board, thinking that, yeah, this is useful stuff, right. Then maybe they'll put their mind to it and actually solve the thing." (I5, PC)

Teaching Goal 2: Monitoring students' thinking (15 instructors). Many instructors thought that problems should allow them to better understand their students thinking. For example: "I am more inclined to have them work out the problem so I can look at the details of what they tried, how they tried to solve it." (I1, PB)

Teaching Goal 3: Leading or not leading students through a problem (22 instructors). These instructors focused on the extent to which teaching should aim at leading students through reasoning processes. All of them thought that problems should lead students through a chain of reasoning, yet 18 also had reservations in doing so since they believed that leading prevents students from thinking through things on their own. For example: "Yeah. Also parts A, B, and C are kind of nice because it helps them organize their thinking a little bit. You see, sometimes when you ask questions with different parts, it helps them, it reminds them that they should set things up in certain ways." (I20, PA); and "You're kind of helping them. You're basically lining up the pieces and then see if they can put them together. This is a strategy that's done ...And you're not really testing their ability to put the whole thing together." (I5, PA)

\section{B. Instructors' value and usage of problem features}

The analysis of how instructors' value specific problem features is based on whether they indicated that the feature promotes or hinders their goals. Similarly, the analysis of the potential usage of these problem features was based on the instructors' identification of the features they would use or never use to meet their goals. The analysis was done independently for each kind of institution. However, except for one case, there were no significant differences between the responses by institution. Consequently, the results are given by institution only for that one case.

A similar figure is used to illustrate the results for each learning and teaching goal (Figs. 4-10). The legend for problem features which is used in all subsequent figures is given in Fig. 3. The left column of each figure shows the features that instructors' value related to the goal. For each feature the figure shows the number of instructors who mentioned it as supportive for developing the goal (positive number on the graph) and the number of instructors who mentioned it as hindering the development of that goal (negative number on the graph).

The next two columns relate to the subset of the instructors who described their usage of the particular problem features that support or hinder the goal. The middle column shows instructors who said they would use (positive) or

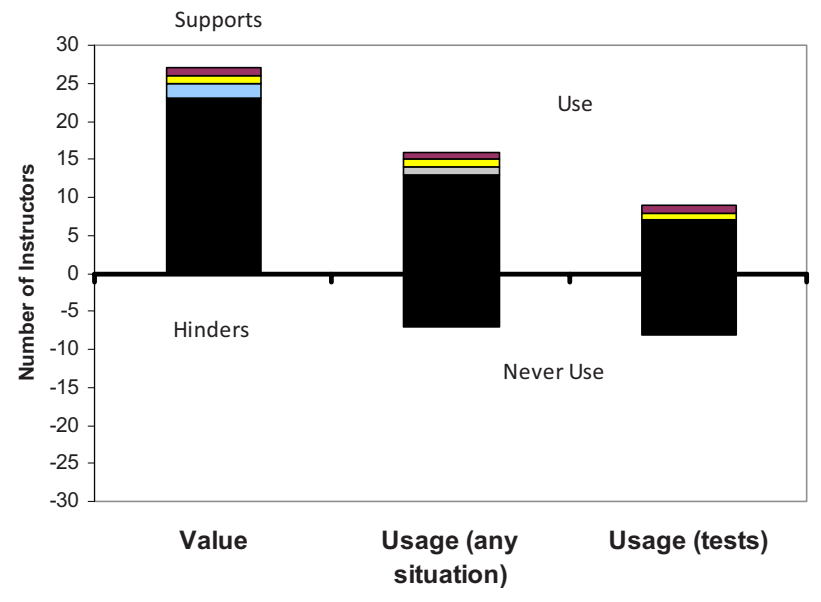

FIG. 4. (Color) Value and usage of problem features related to the learning goal of developing students' physics understanding. The legend is in Fig. 3.

never use (negative) each feature for problems for their course. The right column shows instructors who explicitly said they would use (positive) or never use (negative) each feature in tests or exams. Since the problem features and learning and teaching goals emerged from the interview, instructors did not necessarily comment explicitly on whether or not they would use a feature in exams. Thus the middle column represents all instructors who mentioned they would use (or never use) a feature but did not explicitly mention exams, while the right column represents all instructors who did explicitly mention that the feature might be used (or never used) in exams. An instructor could be included in both the middle and right column, for example if they said that they would use a feature as an example in class (middle column), but would not use that feature on an exam (right column).

It was clear from the interview data that many of the instructors had different criteria for the selection of exam problems than for problems used in other situations in class.

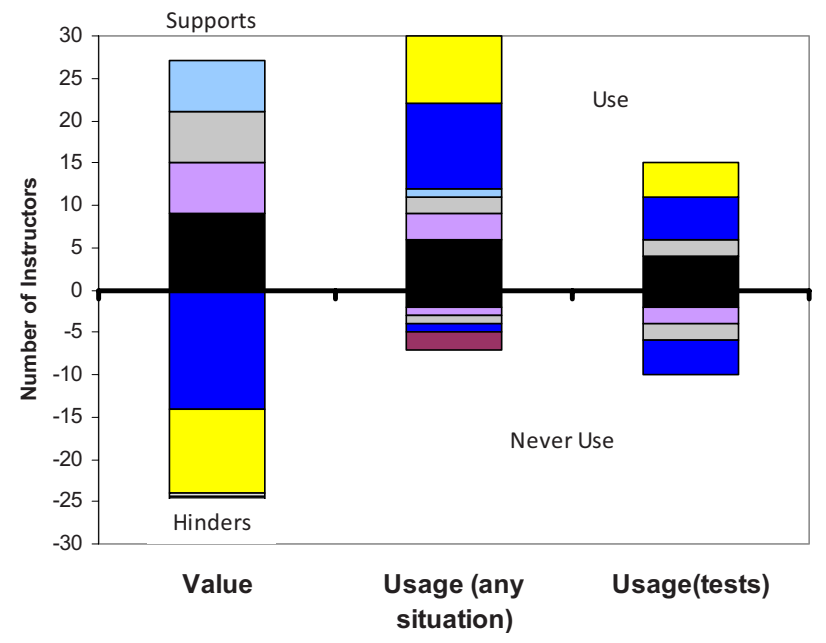

FIG. 5. (Color) Value and usage of problem features related to the learning goal of developing students' ability to plan and explore solution paths. The legend is in Fig. 3 . 


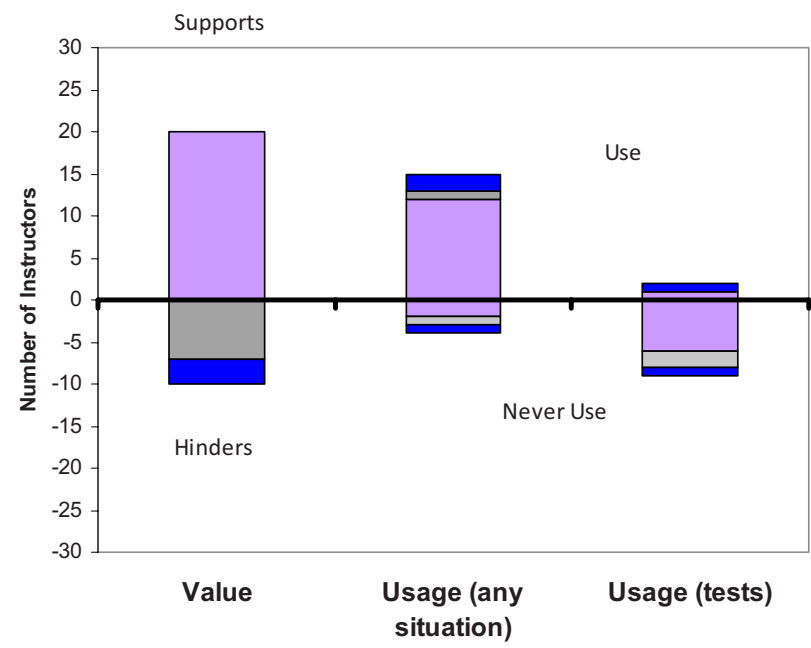

FIG. 6. (Color) Value and usage of features related to the teaching goal of motivating students. The legend is in Fig. 3.

However, instructors were not always explicit about their preferences. Some explained which problem features they value, but did not state explicitly that they would use them, and some stated that they would use them, but did not mention specific situations. For that reason the numbers in the charts do not always add to 30 .

\section{Learning Goal 1: Developing students'physics understanding}

27 instructors mentioned problem features supportive of this goal. Figure 4 shows that the qualitative feature is the main feature considered as supportive of developing students' conceptual physics knowledge (23 instructors). For example: "I might give [problem] D as a very conceptual example. If I wanted to really check on concepts ...it requires more qualitative reasoning." (I3, PD)

Of the 23 instructors that value the qualitative feature for developing students' physics understanding, only about half

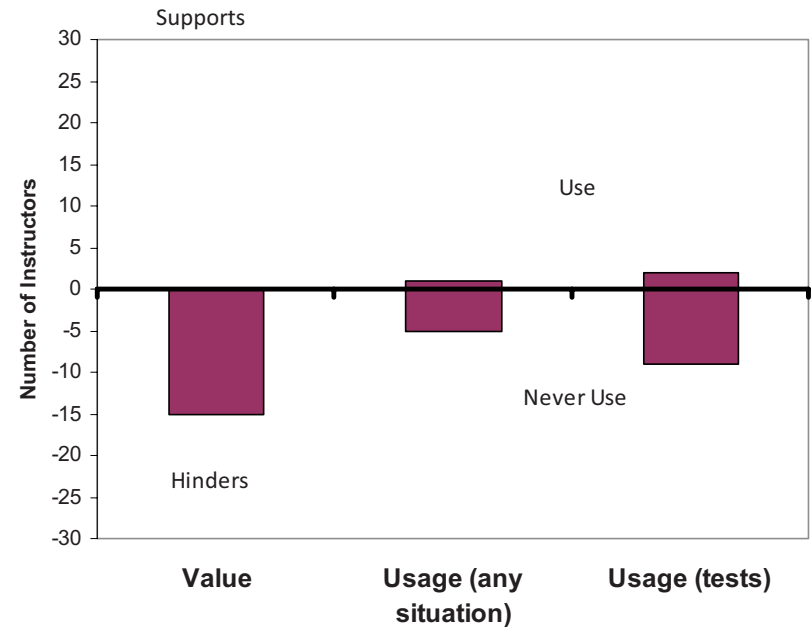

FIG. 7. (Color) Value and usage of problem features related to the teaching goal of monitoring students' thinking. The legend is in Fig. 3. The only problem feature linked to this goal was multiple choice.

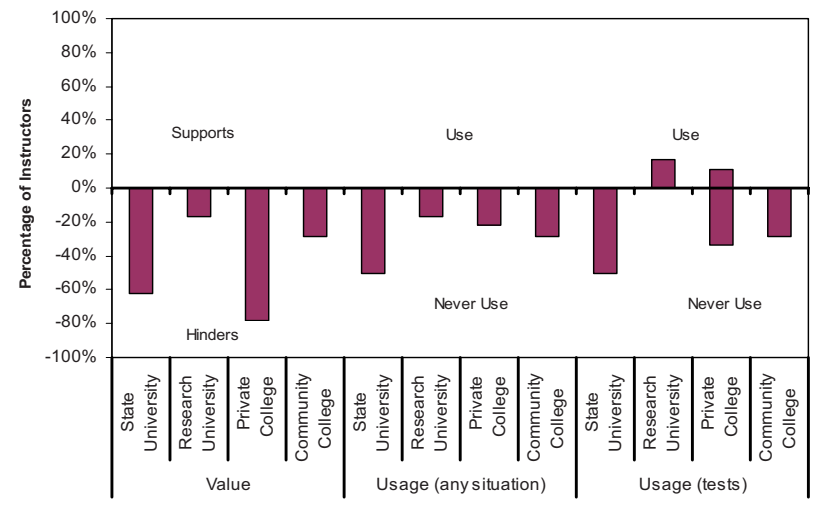

FIG. 8. (Color) Institutional distribution of the value and usage of multiple-choice questions related to the teaching goal of monitoring students' thinking.

(13 instructors) stated they would use it. Only about onethird (7) explicitly said they would use the qualitative feature in exams and about one-third stated they would not use it in exams (8).

\section{Learning Goal 2: Developing students' ability to plan and explore solution paths}

Figure 5 shows that 27 instructors mentioned four problem features as supportive of the goal of developing students' ability to plan and explore solution paths: the qualitative, real-world context, wordy, and complex or multistep features. Nine instructors consider the qualitative feature supportive of this goal. For example: "Their ability to sort through things and identify the physics is being tested much more in this type of problem." (I10, PD); and "So then I'd have some idea about whether they can put the whole thing together." (I5, PD) Six instructors state that the real-world context feature is supportive. For example: "They have to really separate, get the data from the story." (I7, PC) Six instructors consider the wordy feature as supportive of this

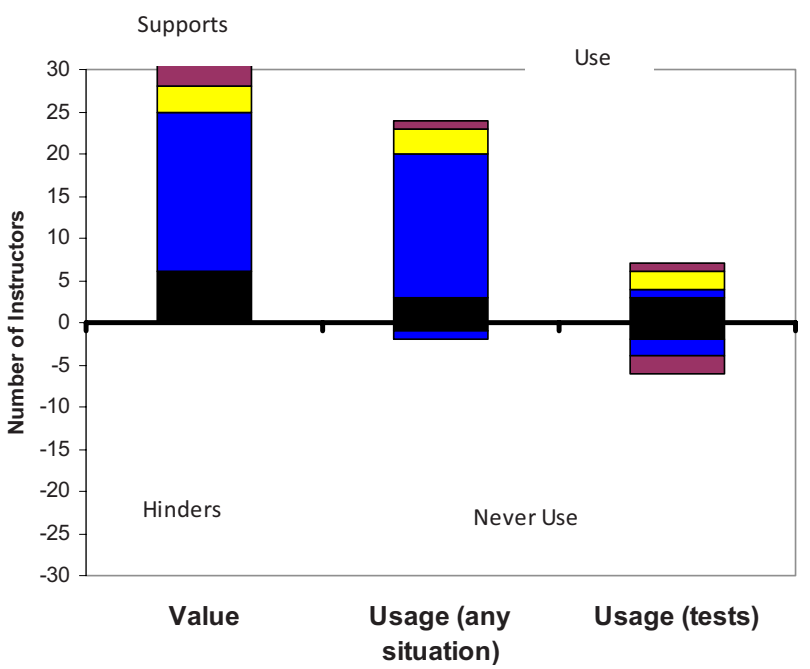

FIG. 9. (Color) Value and usage of problem features related to the teaching goal of leading students through problems. The legend is in Fig. 3. 


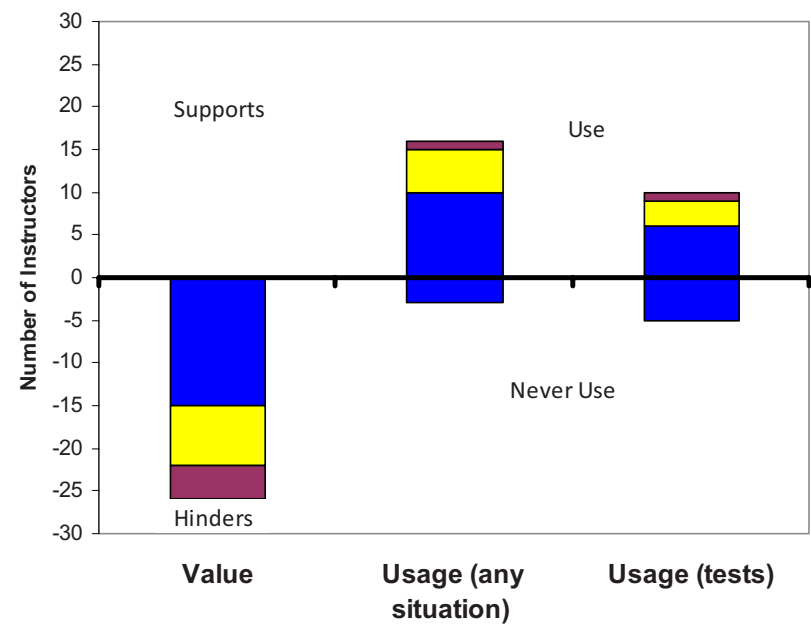

FIG. 10. (Color) Value and usage of problem features related to the teaching goal of not leading students through problems. The legend is in Fig. 3.

goal. For example: "They have to stop and ask themselves what ideas are important." (I9, PC) Finally, 6 instructors state that the complex or multistep feature is supportive. For example: "But on the other hand it just involves them having a deeper understanding of how they have to relate these variables in various situations." (I20, PC)

The broken into parts and given drawing problem features are considered by 24 instructors as hindering the goal of developing students' ability to plan and explore solution paths. Fourteen instructors consider the broken into parts feature as hindering this goal. For example: "Because I like to see that they know, that they have enough creativity to devise their own steps instead of having me devise them for them." (I8, PA) Also 10 instructors state that the given drawing feature hinders this goal. For example: "But again these versions require a little bit of effort on the part of visualizing it and then identifying what principles have to be applied." (I9, PC vs. PD)

This learning goal shows the largest contrast in the value given to problem features and their usage. Although 14 instructors view the broken into parts feature as hindering their students' in developing the ability to plan and explore solution paths, approximately two-thirds of them (ten instructors) state they would use it. Similarly, of the ten instructors who state that the given drawing feature hinders this goal, fourfifths of them (eight instructors) state that they would use it. Of the nine instructors who value the qualitative feature as supporting the goal, only six say they would use it at all and only 4 use it in exams.

\section{Teaching Goal 1: Motivating students}

Figure 6 shows that 20 instructors consider the real-world context feature as supportive of the goal of motivating students. For example: "Good thing about it, they may, see sometimes they complain. Like, we don't know the applications. Here you go." (I11, PC). On the other hand, seven instructors state that the wordy feature hinders this goal. For example: "This problem is still sort of quite artificial; it's just sort of dressed up a little bit." (I12, PC) Only two instructors consider the broken into parts feature as hindering this goal.

Although 20 instructors state that they value the realworld context feature to develop students' motivation, and three-fifths (12 instructors) state they would use it, only one instructor mentions using it on exams and six instructors explicitly state they would not use it on exams. Of the seven instructors who claimed the wordy feature hinders the goal of motivating students, only one of those stated they would use it. Moreover, while three instructors consider the broken into parts feature as hindering this goal, two of them state that they would use it.

\section{Teaching Goal 2: Monitoring students' thinking}

Figure 7 shows that none of the problem features were identified by instructors as supportive of the goal of monitoring students' thinking. On the other hand, the multiple-choice feature is the only feature considered as hindering this goal (15 instructors). For example: "I don't tend to do this [multiple-choice problem] because I want to see their work, so I don't tend to use this kind." (I13, PB). Out of the 15 who find the multiple-choice feature hinders this goal, only one instructor stated that they would use this feature, and 5 stated they never use it. In exam situations, two instructors stated that they would use the multiple-choice feature sometimes (for convenience), and nine stated that they never use it.

Figure 8 shows that although instructors from all the institutions agree that the multiple-choice feature hinders the goal of monitoring students' thinking, they differ in the extent of this agreement and in their use of multiple-choice questions. In particular the research university (RU) instructors differ from state university (SU), community college (CC), and private college (PC) instructors in that they attribute the least importance to this teaching goal. Perhaps this is because the RU instructors often use teaching assistants to grade their students' work. Since they do not actually look at their students' problem solutions, they may be willing to give up the benefit of seeing them. As a practical matter RU instructors tend to teach larger classes so they may choose multiple-choice tests to reduce the time and resources required for grading There is evidence of this consideration in the transcripts of the RU instructors. The SU and the CC instructors are most consistent with their teaching goal of monitoring students' thinking, and state that they would never give multiple-choice exams.

\section{Teaching Goal 3: Leading or not leading students through a problem}

Figures 9 and 10 show that different instructors have contradicting approaches with respect to the teaching goal of leading or not leading students' through a chain of reasoning for a problem solution. There are instructors who believe in the utility of leading the students through a problem and those who do not. Some see leading as useful at the beginning of a course but detrimental later in the course. These instructors are counted in both categories.

The main feature 19 instructors believe supports the leading teaching goal is the broken into parts feature (Fig. 9). For 
example: "So perhaps the first time they're seeing something... you can help them learn the analysis and what steps need to be completed in order to get to the final answer by leading them through it a little bit... I will often lead them through a problem, like by the way it's asked." (I14, PA); and "Yeah, this is good, it kind of guides the student through, you know, the intermediate point."(I15, PA)

This same broken into parts feature is considered as hindering students' learning of problem-solving skills by the 15 instructors who favor the goal of not leading students through a problem (Fig. 10). For example: "But problem B calls on them to create this method, or create a method that's equivalent on their own. And that's why I guess I'd prefer this, because to me that's an important part of it. One of the goals of the course for me is that they become creative with these ideas." (I8, PA vs PB) Similarly, seven instructors consider the given drawing feature as hindering the goal of not leading students. For example: "It [problem A] is doing a lot of the work for the student. They really should make the drawing." (I16, PA)

There is a great deal of conflict between the teaching goals and the problem usage for instructors who do not believe they should lead students through a problem. Out of 15 instructors that find the broken into parts feature hinders their goal of not leading students, ten state they would use this feature and six would use it in exams. Out of the seven instructors that find the given drawing feature hinders their goal of not leading students, five state they would use this feature and three would use it in exams.

\section{Why many instructors do not use problem features they believe support their goals and use those features they believe hinder their goals}

As described above, instructors will use problem features that run counter to their instructional goals. For example, the qualitative feature is believed to promote the two learning goals of developing students' physics understanding and developing their ability to plan and explore solution paths. However, only about one-half of the instructors state they would use this problem feature in general and only about one-third would use it in exams. While 15 instructors believe that the broken into parts feature hinders the students in planning and exploring solution paths, two-thirds of them (ten instructors) state they would use this feature in their problems.

Not all instructors provided reasons for not using problem features that support a goal or for using features that hinder a goal. The hypotheses we frame in this section are based on those few who did provide reasons. These reasons can be divided into the four categories described below.

(1) Avoiding stressful situations. Fourteen instructors gave reasons in this category, all of them in the context of exams. For example, one instructor explained that although he believes the real-world context problem feature supports his goals, he would not use this feature on exams because "This could be very intimidating for a student." (I6, PC) Another instructor stated: "Under the pressures of an exam, I don't think you always have to keep pushing that [having realistic

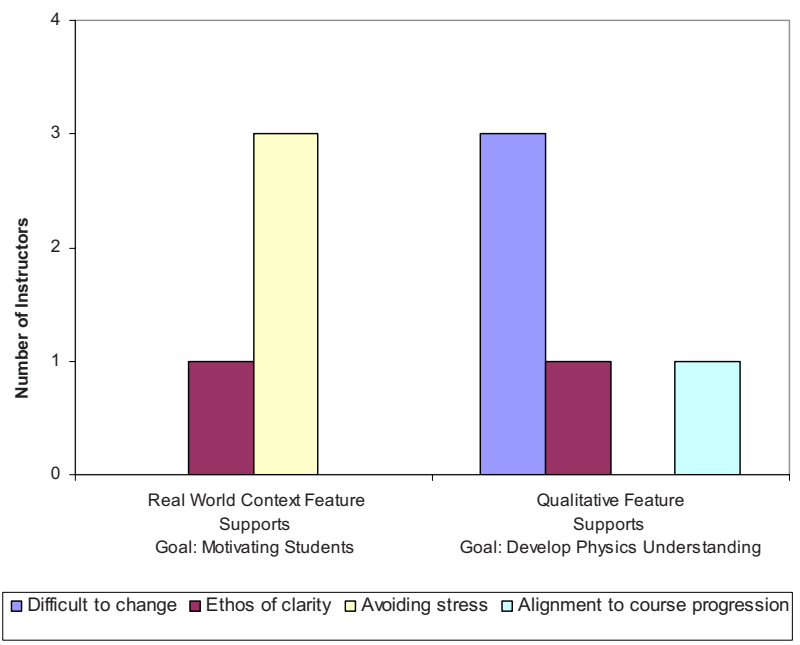

FIG. 11. (Color) Instructors' reasons for not using valued problem features

problems that require students to plan and explore solution paths]." (I20, PC).

(2) The ethos of clarity in a school culture. Nine instructors gave reasons in this category, all of them in the context of exams. These instructors thought it is important to have problems that are completely unambiguous. For example, "I wouldn't have a problem like this on an exam because it's too easy to misinterpret." (I16, PC)

(3) Aligning problem complexity to the course progression. Seven instructors gave reasons in this category. Instructors thought that some problem features were more appropriate for particular stages of the course. For example: "Like if you're teaching dance, you cannot have a student do a double pirouette right away, you have to break it down. So that's part of getting them to the right direction. So that's very appropriate." (I7, PA).

(4) The effort needed to change traditional practice. Six instructors gave reasons in this category. It was common for instructors to mention the time and effort necessary to align the problem features they use more closely with their goals. For example: "I like the problem actually... It's...one of the things that I don't do enough of in the course, but given enough time to change the course I would do more of." (I17, PD); and "...let's say if I had a text book maybe that did a lot of this, I'd probably... [use this kind of problems]." (I5, PC)

Overall, half of the reasons instructors gave about problem usage relate to exam situations. Instructors wish to relieve student stress on exams and, therefore, avoid assigning complex or unfamiliar problems. Instead they use more 'traditional' problems that they consider less intimidating, even though they realize that using such problems conflicts with some of their learning and teaching goals.

The remainder of this section focuses on the reasons the instructors gave for the lack of alignment of the specific problem features they use with their instructional goals. First we consider two features, qualitative and real-world context, that the instructors believe support their goals but that they frequently do not use. These results are summarized in Fig. 11. Then we consider two features, broken into parts and given drawing, that are typically used but believed to hinder 


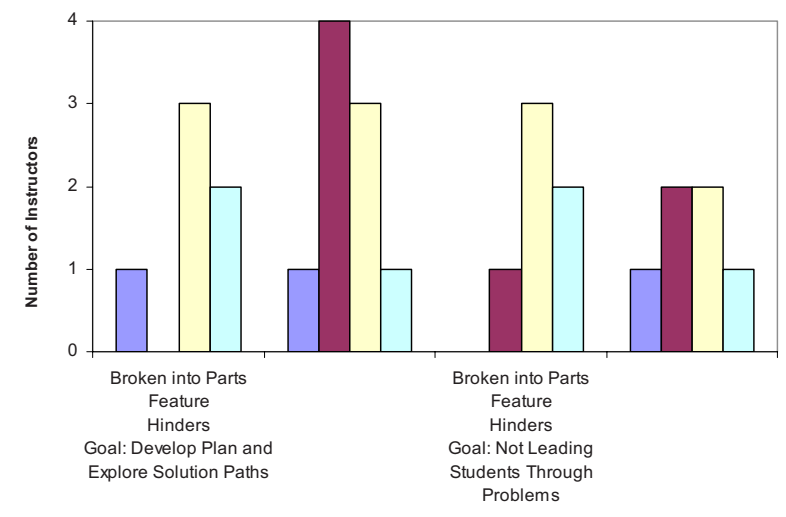

$\square$ Difficult to change $\square$ Ethos of clarity $\square$ Avoiding stress $\square$ Alignment to course progression

FIG. 12. (Color) Instructors' reasons for using problem features they believe hinder a goal.

their goals. These results are summarized in Fig. 12. Because of the small number of instructors reporting reasons for any given feature, we do not think it is wise to make any strong conclusions from this data. We present the categories and hypotheses here as tentative explanations that may be useful in future studies of the alignment between problem features and instructional goals.

The qualitative feature is mentioned primarily in the context of the goal of developing students' physics understanding (Fig. 11). It is considered by 23 instructors as supportive of this goal. Out of those instructors, only 12 state they would use this feature in their problems. The most common stated reason for not using this feature is the effort needed to change traditional practice (three out of the five instructors who gave a reason).

The real-world context feature is mentioned mostly in the context of the goal of motivating students. This feature is considered by 20 instructors as supportive of this goal. Out of these instructors, only 12 state they would use it. The main stated reason for not using this feature is avoiding stressful situations for students, especially in exam situations (three out of the three instructors who gave a reason).

The broken into parts feature is considered by 15 instructors as hindering the goal of developing students' ability to plan and explore solution paths (Fig. 12). Many also state that this feature hinders their goal of not leading students through a problem. Nevertheless, ten of those instructors state they would use this feature in their problems. Their most common reason is avoiding stressful situations for students (three out of the seven instructors giving a reason). For example: "But it's really, it's less intimidating." (I7, PA)

The given drawing feature is believed by ten instructors to hinder the goal of planning and exploring solution paths. Many of them also state it hinders their goal of not leading students through a problem. However, eight of those instructors state they would use this feature in their problems. Their primary stated reasons are the wish to make the problem clear (four out of the four instructors giving a reason) and to avoid stress (three out of the four instructors giving a reason). For example: "Certainly on quizzes and exams, I'd want to be certain that the students understood exactly what
I meant by the problem. So I might, I would be in fact probably more likely to put a picture on ..." (I22, PA)

\section{DISCUSSION}

The interviews analyzed in this study show that faculty teaching introductory physics at a wide range of institutions have overarching learning goals for their problems that are similar the learning goals advocated in the problem-solving research literature. The faculty goal of using problems as a means of helping students develop physics understanding is similar to the educational goal of helping students construct physics knowledge [2]. The faculty goal of developing students' ability to plan and explore solution paths is similar to the educational goal of helping students develop generalized problem-solving skills [3]. In addition, the faculty teaching goal of motivating students through the use of real-world problem contexts is one aspect of the educational goal of introducing students to the nature of scientific culture [4].

The research-based curricular materials developed to help students achieve these goals make use of certain problem features as scaffolding to give novice problem solvers the practice to build and strengthen the thought processes necessary for more expertlike problem-solving. One example of such material is qualitative problems that require students to use physics concepts directly to make predictions without the cognitive interference of mathematics. Another example is the use of complex problems in a realistic context that require students to practice visualization and plan strategies for their solution process.

This study found that physics instructors value problem features similar to those mentioned in the literature as supportive to achieve the above learning goals. For example, instructors believe the qualitative and real-world context features support their learning goals of developing students' physics understanding and developing students' ability to plan and explore solution paths, while the broken into parts and given drawing features are considered as hindering the goal of developing students' ability to plan and explore solution paths. The instructors also have goals for their own teaching that they believe facilitate student learning: motivating students, monitoring students' thinking, and explicitly leading or not leading students through problems. Furthermore, they recognize specific problem features as supporting or hindering the achievement of these teaching goals, such as the real-world context feature (supports the goal of motivating students), the multiple-choice feature (hinders the goal of monitoring students' thinking), and the broken into parts feature (hinders the goal of not leading students through problems). It is interesting to note that instructors express two contradictory approaches as to how they should support their students when solving problems. One is taking the students by the hand (leading) and the other letting the students struggle on their own (not leading). The research literature suggests a third intermediate approach, that of cognitive apprenticeship. In this approach students are typically provided with realistic problems. Instead of providing specific guidance to each problem, students are provided guidance in the form of a more general problem-solving framework [8-10]. 
Students are also provided with examples of how to use the framework (modeling) and feedback (coaching) on their use of the framework.

The study found, however, that physics instructors often do not use features they value (e.g., the real-world context and qualitative features) and even use features they believe hinder the achievement of their own goals (e.g., the broken into parts feature). These instructors recognize that their selection of problem features is not aligned with their goals. A strong reason for this misalignment comes from two global instructor values: reducing the stress on students and the need for clarity in the instructor's communications. Both of these values are triggered most strongly in connection with exams and seem to be linked to a broader value of fairness. In particular, these values drive the inclusion of features they believe hinder the development of students' ability to plan and explore a solution process (such as breaking a problem into parts, or providing a drawing); as well as the exclusion of features desired for motivating students (such as using problems with real-world contexts).

Based on the results of these interviews, we posit that physics faculty understand the merits of implementing the types of problems advocated by research-based curriculum developers. Both have the same sets of learning goals for students and recognize the same problem features to aid in achieving those goals. Although this is also true for most of faculty teaching goals, there is considerable disagreement, often internal to a given instructor, about the value of leading a student through the solution within the structure of a problem. We suggest that dissemination efforts emphasize the areas of agreement and specifically address the issue of leading or not leading students through problems.
The dissemination of research-based problem features, however, depends on more than the congruence of these goals, the availability of problems with the desired features, and evidence of the efficacy of those features in meeting the goals. We suggest that dissemination efforts explicitly recognize instructors' internal conflict between their learning and teaching goals that are aligned with desirable problem features and their values of clarity of presentation and minimizing student stress, especially on exams. For students, exams are the manifestation of the course goals and thus significantly determine their learning behavior. By not using on exams the problem features that they believe lead to important student learning, instructors give up those goals for their course. To significantly improve the problems used in introductory physics classes, dissemination efforts must directly address the instructor values of reducing stress on students and clarity of presentation

\section{ACKNOWLEDGMENTS}

We wish to thank the physics faculty members who gave their valuable time to participate in this study. We wish to thank Yetty Varon, the statistician of the science teaching department at the Weizmann Institute of Science, and Vincent Kuo, now at the Colorado School of Mines, for their help in analyzing the data. We appreciate the support of the University of Minnesota, School of Physics and Astronomy; the University of Minnesota, Department of Curriculum and Instruction; and the Weizmann Institute of Science, Department of Science Teaching. This work was primarily supported by the National Science Foundation Grant No. DUE9972470.
[1] C. Bereiter and M. Scardamalia, Knowing, Learning and Instruction: Essays in Honor of Robert Glaser, edited by L. B. Resnick (Erlbaum, Hillsdale, NJ, 1989).

[2] J. P. Smith, A. A. DiSessa, and J. Roschelle, Misconceptions reconceived: A constructivist analysis of knowledge in transition, J. Learn. Sci. 3, 115 (1994).

[3] F. Reif, Millikan Lecture 1994: Understanding and teaching important scientific thought processes, Am. J. Phys. 63, 17 (1995).

[4] R. Millar, Connecting Research in Physics Education with Teacher Education, edited by A. Tiberghien, E. L. Jossem, and J. Barojas (I.C.P.E. International Committee of Physics Education, 1998).

[5] P. Heller and M. Hollabaugh, Teaching problem solving through cooperative grouping, Part 2: Designing problems and structuring groups, Am. J. Phys. 60, 637 (1992).

[6] A. Van Heuvelen, Overview, Case Study Physics, Am. J. Phys. 59, 898 (1991).

[7] E. Etkina, A. Van Heuvelen, S. White-Brahmia, D. T. Brookes, M. Gentile, S. Murthy, D. Rosengrant, and A. Warren, Scientific abilities and their assessment, Phys. Rev. ST Phys. Educ. Res. 2, 020103 (2006).
[8] J. Heller and F. Reif, Prescribing Effective Human Problem Solving Processes: Problem Description in Physics, Cogn. Instruct. 1, 177 (1984).

[9] K. Heller, Competent Problem Solver-Calculus Version (Thomson, Mason, $\mathrm{OH}, 2006)$.

[10] J. P. Mestre, R. J. Dufresne, W. J. Gerace, P. T. Hardiman, and J. S. Touger, Promoting skilled problem-solving behavior among beginning physics students, J. Res. Sci. Teach. 30, 303 (1993).

[11] L. C. McDermott, Oersted Medal Lecture 2001: "Physics Education Research-The Key to Student Learning", Am. J. Phys. 69, 1127 (2001).

[12] C. H. Crouch and E. Mazur, Peer Instruction: Ten Years of Experience and Results, Am. J. Phys. 69, 970 (2001).

[13] S. E. Dreyfus and H. L. Dreyfus, A Five-Stage Model of the Mental Activities Involved in Directed Skill Acquisition, Storming Media, http://www.stormingmedia.us/15/1554/ A155480.html (1980).

[14] J. H. Larkin, Processing information for effective problemsolving, Eng. Educ., Eng. Educ. 70, 285 (1979).

[15] C. Singh, When physical intuition fails, Am. J. Phys. 70, 1103 (2002).

[16] D. Fortus, Learning: The importance of learning to make as- 
sumptions, Sci. Educ. 93, 86 (2009).

[17] D. Maloney, Handbook of Research on Science Teaching and Learning, edited by D. Gabel, MacMillan, New York, 1994).

[18] J. H. Larkin, J. McDermott, D. P. Simon, and H. A. Simon, Expert and novice performance in solving physics problems, Science 208, 1335 (1980).

[19] M. T. H. Chi, P. J. Feltovich, and R. Glaser, Categorization and Representation of Physics Problems by Experts and Novices, Cogn. Sci. 5, 121 (1981).

[20] P. T. Hardiman, R. Dufrense, and J. P. Mestre, The relation between problem categorization and problem solving among experts and novices, Mem. Cognit. 17, 627 (1989).

[21] F. Reif and J. I. Heller, Knowledge structures and problem solving in physics, Educ. Psychol. 17, 102 (1982).

[22] M. T. H. Chi and K. A. VanLehn, The content of physics selfexplanations, J. Learn. Sci. 1, 69 (1991).

[23] A. H. Schoenfeld, Handbook of Research on Mathematics Teaching and Learning, edited by D. A. Grouws (Macmillan, New York, 1992).

[24] E. Kim and S.-J. Pak, Students do not overcome conceptual difficulties after solving 1000 traditional problems, Am. J. Phys. 70, 759 (2002).

[25] R. Taconis, M. G. M. Ferguson-Hessler, and H. Broekkamp, Teaching science problem solving: An overview of experimental work, J. Res. Sci. Teach. 38, 442 (2001).

[26] A. Van Heuvelen, Experiment problems for mechanics, Phys. Teach. 33, 176 (1995).
[27] RELATE real-world problem index http://relate.mit.edu/ RwProblems/

[28] Activity Based Physics Thinking Problems in Physics http:// www.physics.umd.edu/perg/abp/think/oscil/index.html

[29] L. C. McDermott, P. S. Shaffer, and the Physics Education Group at the University of Washington, Tutorials in Introductory Physics, 1st ed. (Prentice-Hall, Upper Saddle River, NJ, 2002).

[30] P. Labudde, F. Reif, and L. Quinn, Facilitation of scientific concept learning by interpretation procedures and diagnosis, Int. J. Sci. Educ. 10, 81 (1988).

[31] E. Yerushalmi and C. Polingher, Guiding students to learn from mistakes, Phys. Educ. 41, 532 (2006).

[32] C. Hieggelke, D. Maloney, S. Kanim, and T. O'Kuma, E\&M Tipers: Electricity And Magnetism Tasks: Inspired By Physics Education Research (Pearson Education, Upper Saddle River, NJ, 2006).

[33] K. Cummings, J. Marx, R. Thornton, and D. Kuhl, Evaluating innovation in studio physics, Physics Education Research, Supplement to Am, J. Phys. 67, S38 (1999).

[34] T. Foster, Unpublished Doctoral Dissertation, University of Minnesota, 2000.

[35] C. Henderson, E. Yerushalmi, K. Heller, P. Heller, and V. Kuo, Physics Faculty Beliefs and Values about the Teaching and Learning of Problem Solving Part II: Procedures for Measurement and Analysis, Phys. Rev. ST Phys. Educ. Res. 3, 020110 (2007). 